\title{
Precisamos falar sobre futebol, precisamos falar sobre a mulher nesse espaço esportivo
}

\author{
We Need to Talk about Football, \\ We Need to Talk about the Woman in this Sportive Space
}

\author{
Naiara Souza da Silva \\ Universidade Federal de Pelotas (UFPEL), Pelotas/Brasil \\ Doutoranda em Letras, UFPEL \\ naiaraa_souza@hotmail.com
}

\begin{abstract}
RESUMO: Este texto refere-se a reflexões oriundas da tese Futebol e ideologia: a língua e a tatuagem no discurso de sujeitos torcedores da dupla Bra-Pel, escrita a partir dos pressupostos teóricos da Análise do Discurso (AD) de tradição em Michel Pêcheux. Tratamos do futebol enquanto um potente dispositivo de interpelação em que dedicamos atenção aos dois clubes predominantes que compõem o clássico futebolístico da cidade de Pelotas/RS, nominados Esporte Clube Pelotas e Grêmio Esportivo Brasil. Especificamente, aqui, trazemos um recorte que diz respeito às mulheres torcedoras do Pelotas quando materializam em seus corpos tatuagens representativas do seu time de preferência. Nossa preocupação centra-se na seguinte questão: como o discurso da heteronormatividade irrompe no corpo-tatuado do sujeito torcedor mulher? Nesse caminho, nosso objetivo é compreender os efeitos de sentido produzidos pelas tatuagens por nós selecionadas a fim de observar, problematizar, refletir e buscar entender que discursos são predominantes no espaço futebolístico.
\end{abstract}

Palavras-CHAVE: Futebol; Tatuagem; Sentido.

ABSTRACT: This text refers to reflections from the doctoral thesis Football and Ideology: the language and the tattoo in the discourse of subjects supporters of the double Bra-Pel, written from the theoretical assumptions of Discourse Analysis (AD) of tradition in Michel Pêcheux. We understand the football as a powerful interpellation and we dedicate attention to the two predominant clubs that make up the classic football of the city of Pelotas/RS, nominated Esporte Clube Pelotas and Grêmio Esportivo Brasil. Specifically, here, we present a part that refers to women fans of the Pelotas when they materialize in their bodies tattoos representative of their team of preference. Our concern is centered on the following question: how does the discourse of heteronormativity erupt in the body-tattooed of the women fan subject? In this way, our objective is to understand the effects of sense produced by the tattoos selected by us in order to observe, problematize, reflect and seek to understand what discourses are predominant in the football space.

KEYwoRDS: Football; Tattoo; Sense. 


\section{CONSIDERAÇõES INTRODUTÓRIAS ${ }^{1}$}

0 presente trabalho refere-se a reflexões da tese de doutorado intitulada Futebol $e$ Ideologia: a língua e a tatuagem no discurso de sujeitos torcedores da dupla Bra-Pel, desenvolvida a partir dos pressupostos teóricos da Análise do Discurso (AD) de tradição em Michel Pêcheux, sob orientação da Professora Aracy Graça Ernst, no Programa de Pós-Graduação em Letras vinculado à Universidade Federal de Pelotas (UFPEL).

Nesse estudo, dedicamos atenção aos dois clubes predominantes que compõem o clássico da cidade de Pelotas, situada no interior sul do estado do Rio Grande do Sul (RS), nominados Esporte Clube Pelotas e Grêmio Esportivo Brasil. Essa dupla adversária reconhecida como Bra-Pel é considerada por muitos estudiosos como um dos maiores clássicos do interior sul do RS devido à fidelidade e à paixão de ambas as torcidas. De acordo com Osório e Amaral, ${ }^{2}$ autores que se dedicaram em reviver lembranças e (re)unir informações sobre a rivalidade Bra-Pel na obra A história dos Bra-Péis, "sem o Bra-Pel, não poderíamos nunca compreender o esporte das multidões. Ele é a alma e a própria vida do nosso futebol. Mais que isso, é uma das maiores manifestações culturais que a cidade já produziu". Vejamos algumas informações básicas sobre os dois:

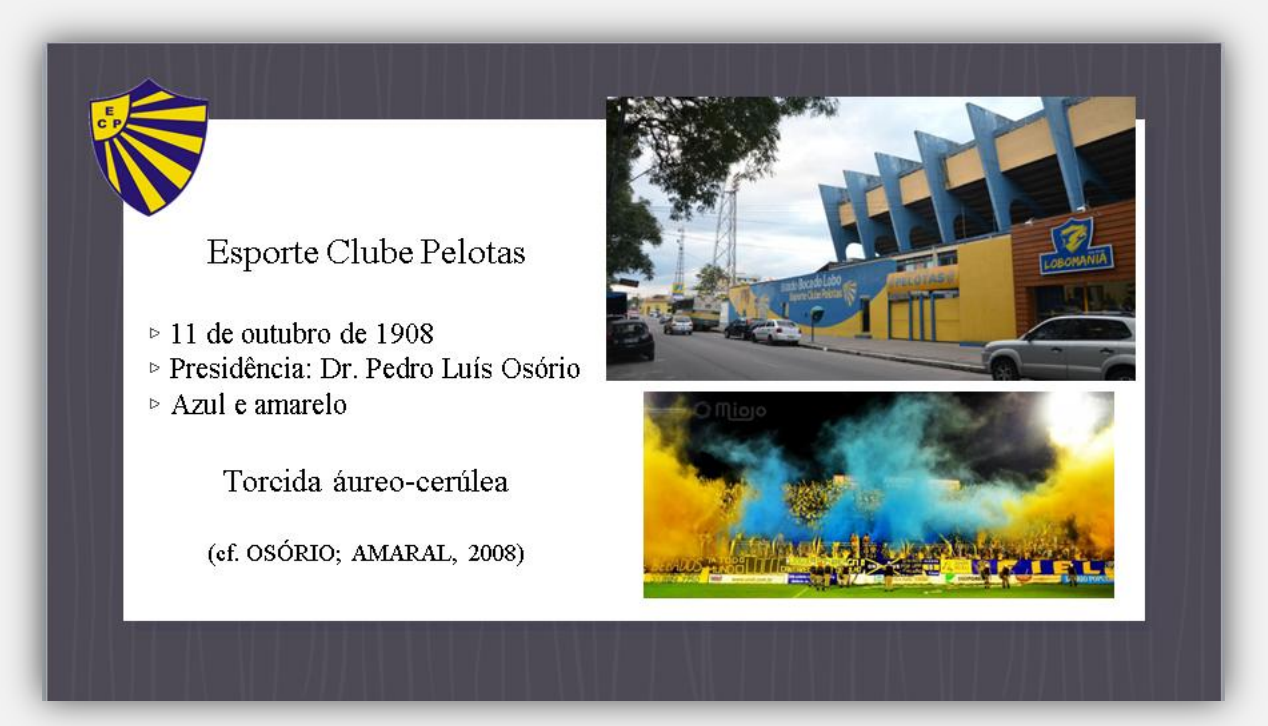

Fig. 1 - Esporte Clube Pelotas. Fonte: Arquivo da pesquisa.

\footnotetext{
${ }^{1}$ Trabalho apresentado no III Simpósio Internacional de Estudos sobre Futebol, em setembro de 2019, organizado pelo Museu do Futebol, LUDENS (FFLCH-USP), Ludopédio e pela PUC-SP. ${ }^{2}$ OSÓRIO; AMARAL. A história dos Bra-Péis, p. 50.
} 


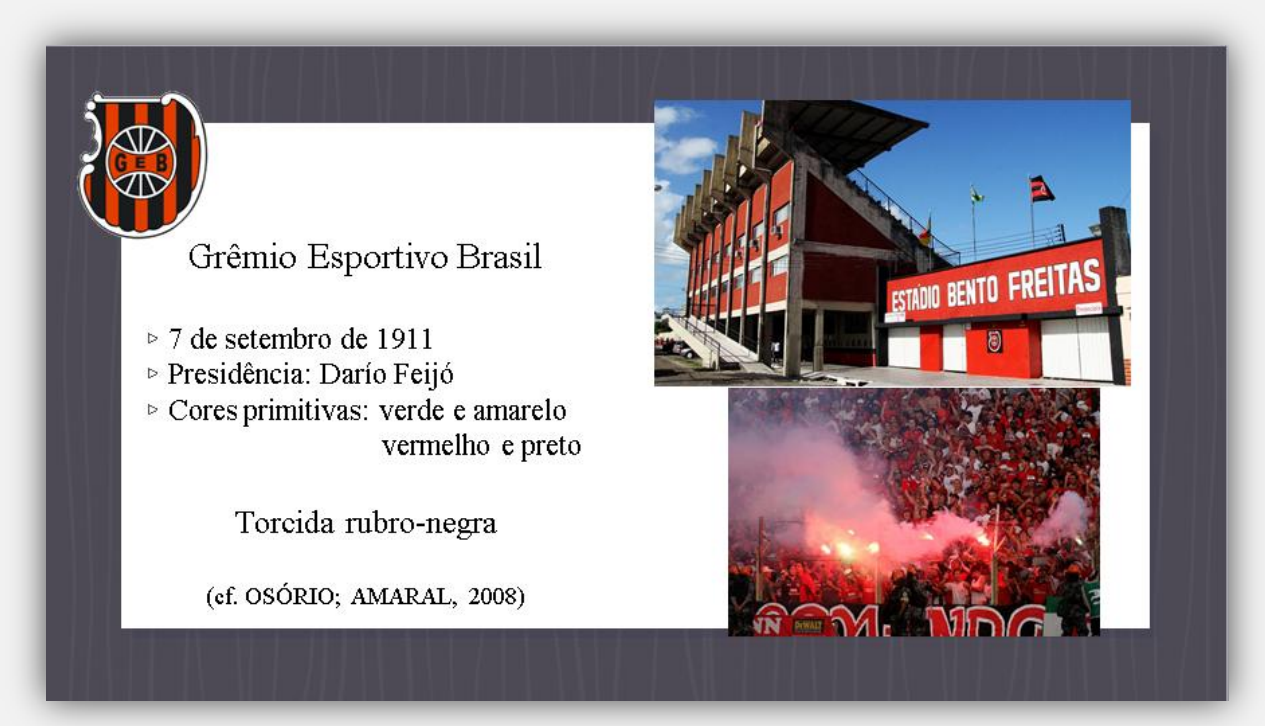

Fig. 2 - Grêmio Esportivo Brasil. Fonte: Arquivo da pesquisa.

0 interesse pela temática do futebol diz respeito ao incômodo gerado pelo seu funcionamento em nossa sociedade, seus mecanismos ideológicos e seu papel na (re)produção de determinados sentidos e estereótipos, somado ao interesse de compreender o modo como esse esporte interpela os sujeitos torcedores.

Dito em outras palavras, acreditamos que o papel do futebol em nossa sociedade vai além de uma modalidade esportiva, configurando-se de uma maneira que precisa ser analisada, pois ele nos fornece subsídios para o entendimento das relações sociais que permeiam a sociedade brasileira. Veríssimo, ${ }^{3}$ em uma de suas crônicas, essa chamada Para que serve o futebol, provocou-nos a refletir sobre o assunto, na medida em que, o autor dá voz a um alienígena que ao visitar a Terra, reconhece que o futebol existe em nosso país para representar o desperdício nacional em todas as esferas, econômica, política e cultural.

$\mathrm{Na}$ conclusão do alienígena, perplexo com o que viu, "a função do futebol, no Brasil, é ser metáfora",4 e se bem entendemos a provocação do autor nessa crônica citada, consideramos importante a discussão que propomos quando assumimos o entendimento de que o futebol excede a prática esportiva e a forma de entretenimento, funcionando como um processo que pode forjar tensões entre instâncias distintas, capaz

\footnotetext{
${ }^{3}$ VERÍSSIMO. Para que serve o futebol, p. 19-20.

${ }^{4}$ VERÍSSIMO. Para que serve o futebol, p. 19-20.
} 
de instaurar discursos que fazem funcionar o motor da ideologia, de acordo com os pressupostos teóricos de nosso precursor Michel Pêcheux. ${ }^{5}$

Rodhden, Azevedo e Azambuja, ${ }^{6}$ anunciam a importância de estudos que contemplem a temática futebolística já que se considera o "país a terra desse esporte" (p. 08). 0 futebol possibilita-nos, assim, olharmos a sociedade e os sujeitos que dela fazem parte. Rinaldi nos lembra de que

o futebol expressa a sociedade, pois o jogo está na sociedade tanto quanto a sociedade está no jogo. Ambos expressam-se mutuamente, principalmente no que se refere à subjetividade das relações estabelecidas dentro do contexto de uma partida de futebol, as transgressões às regras, à ordem e à desordem, o envolvimento da torcida com seu time de coração, chorar ou se alegrar, brigar ou festejar. 0 futebol teria, assim, uma riqueza simbólica, que poderia expressar a sociedade brasileira. ${ }^{7}$

E é essa riqueza simbólica citada por Rinaldi ${ }^{8}$ que nos interessa estudar, dada à representação do futebol enquanto "fenômeno social do Brasil"9, que joga com as subjetividades, com afetos e desafetos dos sujeitos. Assim, diante de um crescente cenário de estudos nesse campo futebolístico há esperança na pesquisa científica, e pela necessidade de estudos multidisciplinares para a compreensão do futebol, acreditamos que a Análise de Discurso pode contribuir nesse quadro teórico de trabalhos, enquanto uma ciência que se funda no entremeio de outras disciplinas e tem como premissa a questão interdisciplinar.

Dito isso, acrescentamos que a AD, conforme relata o próprio Pêcheux 10 , "surgiu na forma de um trabalho político e científico especializado, visando a tomar uma posição em um campo logicamente estabilizado (demonstrando/criticando/justificando este ou aquele discurso, inscrito nesta ou naquela posição)".

Nesse caminho, neste trabalho precisamente, trazemos um recorte da tese que diz respeito às mulheres torcedoras do Esporte Clube Pelotas quando materializam em seus corpos tatuagens representativas do seu time de preferência. A tatuagem, a nosso

\footnotetext{
${ }^{5}$ GADET; HAK. Por uma análise automática do discurso: uma introdução à obra de Michel Pêcheux.

${ }^{6}$ ROHDEN; AZEVEDO; AZAMBUJA. Aquecimento: a filosofia aplicada ao futebol, p. 7-23.

${ }^{7}$ RINALDI. Futebol: manifestação cultural e ideologização, p. 171.

${ }^{8}$ RINALDI. Futebol: manifestação cultural e ideologização, p. 167-172.

${ }^{9}$ GUTERMAN. O futebol explica o Brasil: uma história da maior expressão popular do país, p. 4.

${ }^{10}$ PÊCHEUX. O estranho espelho da Análise de Discurso, p. 22.
} 
entender, ao se materializar no corpo, textualmente, se constitui enquanto discurso ${ }^{11}$. Através dela, num processo de textualização do corpo, o sujeito grava no tecido da pele o seu desejo, a sua interpretação e a sua interpelação.

Compreendemos, nesse funcionamento discursivo, que os sentidos não estão unicamente no desenho da tatuagem, mas aquém e além dele, pois se trata de um gesto de significação de sentidos múltiplos que simbolizam, configurando uma posição-sujeito e, não pode ser entendida, dessa forma, como se seu sentido fosse transparente tampouco evidente.

Orlandi concentra sua atenção na tatuagem como um processo de individua(liza)ção do sujeito que se tatua, e também nos sentidos formulados se pensados em relação com a sociedade ao qual este sujeito tatuado faz parte. ${ }^{12}$ Esse processo de individua(liza)ção decorre, no seu entendimento, da necessidade do sujeito de individualizar seu corpo no/do corpo social, por meio do gesto simbólico-histórico de inscrever a letra na pele.

Se bem entendemos a autora, a tatuagem estabelece um campo de significação que compreende o próprio corpo do sujeito como um espaço, uma região de sentidos escritos na pele, produzindo efeitos de sentidos próprios a determinadas condições políticas e ideológicas. Com relação aos sujeitos torcedores mulheres, nosso foco, a tatuagem possibilita sua individualização do outro, do time adversário, seja ele o Brasil de Pelotas, mas também do outro sujeito torcedor do Pelotas homem, a partir de sentidos que podem ser colocados em jogo no processo de subjetivação.

\section{O NOSSO GESTO ANALÍTICO: UM OLHAR SOBRE A TEXTUALIZAÇÃO DE DISCURSOS HETERONORMATIVOS NAS TATUAGENS FUTEBOLÍSTICAS}

Com base no que foi disposto até o momento, salientamos que a nossa preocupação está na seguinte questão: como o discurso da heteronormatividade irrompe no corpotatuado do sujeito torcedor mulher? E nosso objetivo específico trata-se de compreender os efeitos de sentido produzidos pelas tatuagens por nós selecionadas, materializadas por duas torcedoras distintas.

\footnotetext{
11 SILVA. Tatuagens: sujeitos e sentidos.

${ }^{12}$ ORLANDI. À flor da pele: indivíduo e sociedade, p. 187-197.
} 
Sendo assim, enfatizamos que precisamos falar sobre futebol, precisamos falar sobre a mulher nesse espaço esportivo. Precisamos, a nosso ver, observar, problematizar, refletir e buscar compreender que discursos são predominantes no espaço futebolístico, pois não há prática que seja desprovida de sentido como sabemos. Abaixo apresentamos as tatuagens:

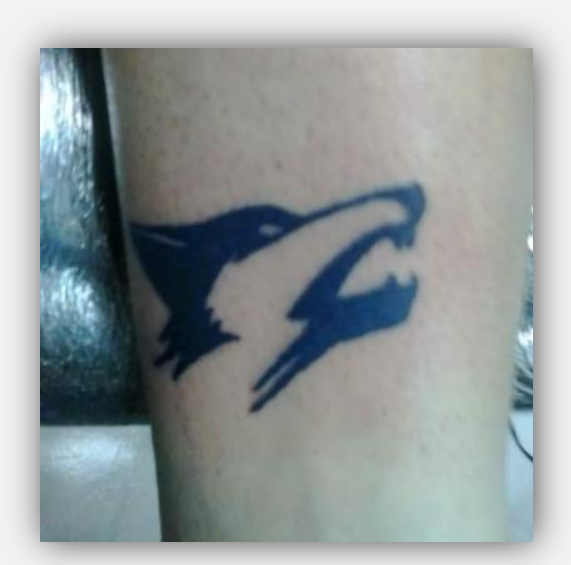

Fig. 3 - Tattoo 1 do sujeito torcedor mulher 1 Fonte: Arquivo da pesquisa.

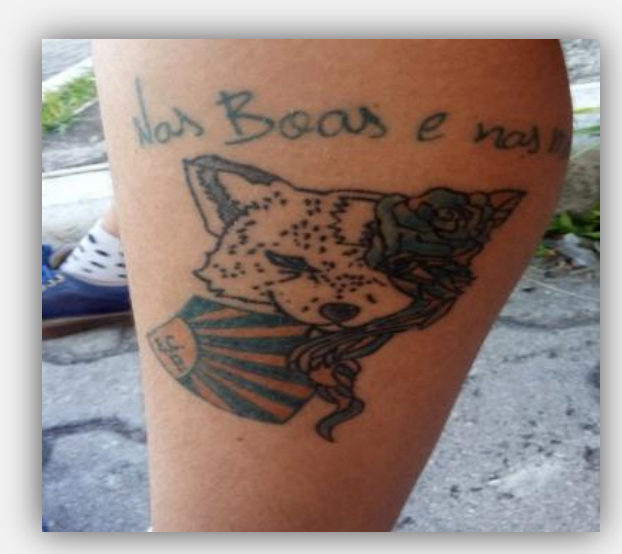

Fig. 4 - Tattoo 1 do sujeito torcedor mulher 2 Fonte: Arquivo da pesquisa.

De acordo com nosso gesto de leitura empreendido, essas tattoos alusivas ao lobo, mascote do Pelotas, considerado símbolo do clube, produzem efeitos de sentidos diferentes. Atentamos à primeira tatuagem que materializa a figura de um lobo, macho. Pensando num universo logicamente estabilizado em que circulam sentidos determinantes do universo do homem e da mulher, onde se encontra o futebol, o sujeito torcedor mulher 1 não rompe com estereótipos, ao contrário, ao textualizar esse lobo, macho, traz no fio de seu discurso efeitos que reproduzem sentidos que reforçam discursos provenientes de uma sociedade patriarcal.

Observando as próprias palavras do sujeito torcedor mulher 1 que conduziram nossa leitura, temos a ênfase na figura de um lobo, macho, quando falava de suas tatuagens alusivas ao seu time e de seu sentimento por ele. Na formulação do sujeito: "eu tenho três tatuagens do Pelotas, relacionadas ao time. ${ }^{13}(+)$ Eu tenho o símbolo do Pelotas, tenho (+) o início, a primeira frase do hino e um lobo mais ou menos customizado na perna".14

\footnotetext{
13 SUJEITO 1. Entrevista sobre as tatuagens alusivas ao time de futebol de preferência.

${ }^{14}$ Esse sinal (+) por nós utilizado refere-se a uma pausa de menos de cinco segundos na fala do sujeito torcedor mulher 1 quando entrevistada para a tese. O sinal faz parte do sistema de
} 
A essa tatuagem do lobo, então, podemos somar outra citada pelo sujeito:

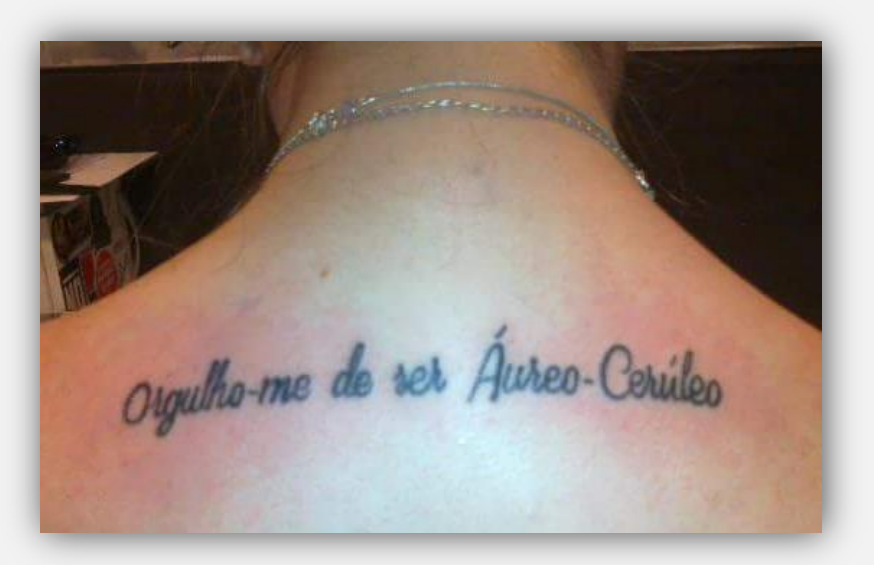

Fig. 5 - Tattoo 2 do sujeito torcedor mulher 1. Fonte: Arquivo da pesquisa.

Essa tatuagem utiliza o enunciado "Orgulho-me de ser Áureo-Cerúleo", parte do hino do time. Nossa atenção está, principalmente, na denominação “Áureo-Cerúleo" que se trata de uma referência às cores representativas do clube, amarelo e azul. Nessa tattoo, pela nossa interpretação, entendemos que o sujeito continua a posicionar-se ideologicamente interpelado por pressupostos heteronormativos, quando se utiliza do gênero masculino, através do artigo "-o", ao invés do feminino, "-a”, "Áureo-Cerúlea”, torcida feminina que já existe inclusive.

Mariani salienta que "o denominar não é apenas uma aspecto do caráter de designação das línguas. Denominar é significar, ou melhor, representa uma vertente do processo social de produção de sentidos".15 Nesse sentido, acrescentando um pressuposto pecheuxtiano, podemos atentar que a denominação não é aleatória, mas uma interpretação no nível do simbólico - não esquecendo que o sujeito desde sempre é chamado a interpretar. Assim, ao denominar-se "áureo-cerúleo" o sujeito torcedor mulher 1 coloca em funcionamento as relações de força existentes na nossa sociedade, os embates sócio-históricos, as imposições, os silenciamentos.

Em suma, ambas as tatuagens (Figuras 3 e 5) reproduzem na sua textualização, discursos hegemônicos vigentes socialmente. Pensando em nossa formação social,

análise sugerido por Luiz Antônio Marcuschi para uma transcrição de conversas "limpa e legível". Adotamos sua metodologia, elaborada com base em estudos de conversação entre falantes, na tese para a transcrição das entrevistas realizadas com os sujeitos torcedores, homens e mulheres, da dupla Bra-Pel. (Grifos nossos).

${ }^{15}$ MARIANI. O PCB e a imprensa: os comunistas no imaginário dos jornais, p. 118. 
entendemos que a ideologia, parafraseando Pêcheux, é um processo que produz e mantém as diferenças necessárias ao funcionamento das relações sociais de produção em uma sociedade dividida em classes. ${ }^{16}$

Nesse sentido, a reflexão sobre as relações de poder, em especial as relações de gênero, torna-se aqui fundamental. Para tanto, recorremos ao estudo de Goellner, Silva e Botelho-Gomes que já trata da questão de gênero com relação ao esporte. ${ }^{17}$ No entendimento das autoras, o futebol enquanto prática cultural é generificado e generificador, ou seja, no contexto futebolístico as práticas são perpassadas por funcionamentos de (re)produção de relações de poder, onde se confere maior visibilidade aos sujeitos homens.

$\mathrm{Na}$ ótica das autoras, essa centralidade no futebol praticado por homens, e aqui nós nos referimos tanto a sujeitos atletas quanto a sujeitos torcedores, é reforçada pela mídia que (re)produz diariamente saberes historicamente construídos, valores arraigados no sistema patriarcal. Para elas,

é fácil imaginar o quanto uma alteração na forma de exibir o futebol vivenciado pelas mulheres poderia potencializar o esporte, conferindolhes outros sentidos e significados. Mais do que isso, faria justiça a quem, desde há muito tempo, também o protagoniza e constrói cotidianamente a sua história. ${ }^{18}$

Essa posição protagonista no futebol do sujeito mulher evidenciada pela utopia de Goellner, Silva e Botelho-Gomes, em que tal sujeito marca a sua posição, resiste ao enquadramento e ressignifica sentidos, pode ser relacionado ao gesto de textualizar seu corpo do sujeito torcedor mulher $2 .{ }^{19}$ Fazemos essa aproximação a partir da ruptura com o discurso anterior, instaurada pela materialização da tattoo 1 do sujeito torcedor mulher em questão (Figura 4).

Nessa tatuagem o sujeito ressignifica a figura do lobo, macho, para uma loba, fêmea, deslocando um sentido construído historicamente para a posição-sujeito que imaginariamente se inscreve, seja ela, de torcedora, mulher, num espaço que é

\footnotetext{
${ }^{16}$ GADET; HAK. Por uma análise automática do discurso: uma introdução à obra de Michel Pêcheux. ${ }^{17}$ GOELLNER; SILVA; BOTELHO-GOMES. A sub-representação do futebol praticado por mulheres no jornalismo esportivo de Portugal: um estudo sobre a Algarve Women's Football Cup, p. 171-189.

${ }^{18}$ GOELLNER; SILVA; BOTELHO-GOMES. A sub-representação do futebol praticado por mulheres no jornalismo esportivo de Portugal, p. 185.

${ }^{19}$ GOELLNER; SILVA; BOTELHO-GOMES. A sub-representação do futebol praticado por mulheres no jornalismo esportivo de Portugal, p. 171-189.
} 
predominantemente do homem. Podemos escrever que, ao tatuar uma loba, o sujeito torcedor mulher 2 resiste ao enquadramento, à manipulação, do que se pode e/ou não pode ser ou fazer na sociedade, e ao resistir, materializa seu enfrentamento na pele.

Utilizando-nos de sua formulação, o sujeito enuncia: "é uma loba com o escudo, 'Nas Boas e nas más!', e não importa se perder ou se ganhar, vai ser sempre a minha paixão". ${ }^{20}$ A utilização do substantivo no gênero feminino que substitui a vogal final "-o" do masculino, para a vogal "-a", com o precedente indefinido também no feminino, destaca sua particularidade, e não representa no fio do discurso apenas uma mudança lexical, mas a própria interpretação do sujeito torcedor mulher 2 e sua resistência no meio futebolístico.

Dessa forma, retomamos a teoria a qual nos filiamos para chamar a atenção para as evidências dos sentidos que pressupõem a transparência da linguagem, na qual uma palavra designa uma coisa ou possui uma única significação; tratando-se do futebol, nosso objeto de estudo, procuramos empreender uma leitura que desfaça a evidência de certos sentidos que foram construídos ao longo do percurso de legitimação do futebol no país, uma leitura centralizada nos ditos e nos não-ditos, nas continuidades e nas descontinuidades, nos pontos de completude (mera ilusão) e naqueles de embaraço a respeito desse esporte.

Em nossa última consideração, assim, evidenciamos que se pode negligenciar, silenciar, apagar os efeitos da ideologia e da história, mas nem por isso eles estão menos presentes nos processos discursivos e nas práticas cotidianas. A ideologia está na nossa frente, naturalizada, precisamos olhar! Enfatizamos: precisamos ser sensíveis às incoerências, às contradições, às resistências, e talvez, por isso, concordamos com o alienígena de Veríssimo, ${ }^{21}$ quando afirma que o futebol, no Brasil, é um mau negócio. Mas que possamos deixar a bola rolar, e através de nossas discussões dar visibilidade aos sujeitos torcedores mulheres porque o gesto de torcer por seu time de preferência é capaz de romper barreiras, de resistir!

\footnotetext{
${ }^{20}$ SUJEITO 2. Entrevista sobre as tatuagens alusivas ao time de futebol de preferência. (Grifos nossos, ênfase do sujeito).

${ }^{21}$ VERÍSSIMO. Para que serve o futebol, p. 19-20.
} 


\section{REFERÊNCIAS}

GOELLNER, Silvana Vilodre; SILVA, Paula; BOTELHO-GOMES, Paula. A subrepresentação do futebol praticado por mulheres no jornalismo esportivo de Portugal: um estudo sobre a Algarve Women's Football Cup. Movimento. Porto Alegre, v. 19. n. 3. 2013, p. 171-189.

GUTERMAN, Marcos. O futebol explica o Brasil: uma história da maior expressão popular do país. 1aㅡ. ed. São Paulo: Contexto, 2014.

MARCUSCHI, Luiz. Análise da conversação. 4ª ed. Editora Ática, 1998.

MARIANI, Bethania Sampaio Corrêa. O PCB e a imprensa: os comunistas no imaginário dos jornais. Rio de Janeiro: Revan; Campinas: Editora da Unicamp, 1998.

ORLANDI, Eni Puccinelli. À flor da pele: indivíduo e sociedade. In: Discurso em análise: sujeito, sentido e ideologia. $2^{\mathrm{a}}$ ed. Campinas: Pontes Editores, $2012^{\mathrm{a}}$, p. 187-197. OSÓRIO, Sérgio Augusto; AMARAL, Mário Gayer. A história dos Bra-Péis. Pelotas: Editora Signus, 2008.

GADET, Françoise; HAK Tony. (Org.). Por uma análise automática do discurso: uma introdução à obra de Michel Pêcheux. $4^{\text {a }}$ ed. Trad.: Bethania Mariani et al. Campinas: Editora da Unicamp, 2010 [1990].

PÊCHEUX, Michel. O estranho espelho da Análise de Discurso [Prefácio]. In: COURTINE, Jean-Jacques. Análise do discurso político: o discurso comunista endereçado aos cristãos. Tradução de Cristina de Campos Velho Birck et al. São Carlos: EdUFSCar, 2009, p. 21-26.

RINALDI, Wilson. Futebol: manifestação cultural e ideologização. Revista da Educação Física. Universidade Estadual do Maringá, v. 11, n. 1, 2000, p. 167-172.

ROHDEN, Luiz; AZEVEDO, Marco; AZAMBUJA, Celso. Aquecimento: a filosofia aplicada ao futebol. In: . Filosofia e futebol: troca de passes. Porto Alegre: Sulina, 2012, p. 7-23.

SILVA, Naiara Souza da. Tatuagens: sujeitos e sentidos. 2014. 153f. Dissertação de Mestrado. Universidade Católica de Pelotas - UCPEL. Pelotas, dez. 2014.

SUJEITO 1. Entrevista sobre as tatuagens alusivas ao time de futebol de preferência. [mar., 2017]. Entrevistador: Naiara Souza da Silva. Pelotas, 2017. 1 arquivo mp3 (03:48). 1 fotografia da tatuagem.

SUJEITO 2. Entrevista sobre as tatuagens alusivas ao time de futebol de preferência. [nov., 2016]. Entrevistador: Naiara Souza da Silva. Pelotas, 2016. 1 arquivo mp3 (15:55). 1 fotografia de cada tatuagem - 3 tatuagens.

VERÍSSIMO, Luis Fernando. Para que serve o futebol. In: paixão, poesia e futebol. Rio de Janeiro: Objetiva, 2010, p. 19-20.

Time dos sonhos: 